\title{
Naive tadpoles do not recognize recent invasive predatory fishes as dangerous
}

\author{
Attila Hettyey, ${ }^{1,2,4}$ Kerstin E. Thonhauser, ${ }^{1}$ Veronika Bókony, ${ }^{2}$ Dustin J. Penn, ${ }^{1}$ Herbert Hoi, ${ }^{1}$ \\ and Matteo Griggio ${ }^{1,3}$ \\ ${ }^{1}$ Department of Integrative Biology and Evolution, Konrad Lorenz Institute of Ethology, University of Veterinary Medicine, Vienna, \\ Savoyenstrasse 1A, 1160, Vienna, Austria \\ ${ }^{2}$ Lendület Evolutionary Ecology Research Group, Plant Protection Institute, Centre for Agricultural Research, Hungarian Academy \\ of Sciences, Herman Ottó út 15, 1022, Budapest, Hungary \\ ${ }^{3}$ Department of Biology, University of Padova, Via U. Bassi 58B, 35121, Padova, Italy
}

\begin{abstract}
Invasive alien predators (IAP) are spreading on a global scale - often with devastating ecological effects. One reason for their success may be that prey species fail to recognize them due to a lack of co-evolutionary history. We performed a comprehensive test of this "prey naiveté" hypothesis using a novel approach: we tested whether predator-naive tadpoles of the agile frog (Rana dalmatina) display antipredator behavior upon encountering chemical cues produced by native, invasive (established or recent) or allopatric fishes (four perciforms, four siluriforms, and two cypriniforms). We studied the influence of population origin on predatordetection ability by presenting chemical cues to predator-naive tadpoles that originated from fishless hill-ponds or fish-infested floodplain populations. Before trials, we fed fishes with tadpoles or an alternative food to test whether direct chemical cues from the predator's diet influences the tadpoles' recognition of potential predators. Tadpoles reduced their activity upon exposure to cues from native and long-established invasive perciforms, but not in response to recent invaders, allopatric predators, or to any siluriforms. Also, predators that were previously fed with tadpoles did not universally induce behavioral defensedefenses upon first encounter. Finally, tadpoles originating from isolated hill-ponds exhibited higher baseline activity and responded in weaker fashion than their conspecifics from floodplain populations, which co-exist with predatory fishes. Our results indicate that tadpoles may be vulnerable to invading predatory fishes due to their inability to recognize them as dangerous, though their ability to recognize invasive IAP may evolve rapidly, in fewer than 30 generations.
\end{abstract}

Key words: antipredator behavior; history of coexistence; inducible defense; invasive species; predator recognition.

\section{INTRODUCTION}

One would expect invasive species to be poorly adapted to novel environments upon their arrival, and yet an increasing number of invasive alien species (IAS) are spreading on a global scale. In fact, IAS are one of the leading causes of global ecological problems, impacting native species and communities through predation, vectoring diseases, genetic introgression, reproductive interference, habitat modification, and competition (Clavero and García-Berthou 2005, Davis 2009, McGeoch et al. 2010). Negative impacts can sometimes be mitigated (Davis 2009, McGeoch et al. 2010), but invasions are notoriously difficult to counteract (Davis 2009, Blackburn et al. 2010, Tabak et al. 2015).

The spread of IAS is a "natural experiment" that provides an opportunity to determine why some but not other invading species successfully become established. IAS are typically ecological generalists with short generation times, high rates of growth and reproduction,

\footnotetext{
Manuscript received 15 March 2016; revised 23 June 2016; accepted 5 July 2016. Corresponding Editor: M. C. Urban.

${ }^{4}$ E-mail: hettyey.attila@agrar.mta.hu
}

and high dispersal and competitive abilities (Whitney and Gabler 2008, van Kleunen et al. 2010). Successful IAS may also exhibit high levels of phenotypic plasticity and evolvability, allowing them to rapidly adapt to new conditions (Daehler 2003, Whitney and Gabler 2008). The lack of a shared evolutionary history with native organisms may also affect the success of IAS. This "enemy release hypothesis" suggests that after invading a new environment, IAS escape many of their parasites, predators, and competitors (Keane and Crawley 2002). The "prey naiveté hypothesis" suggests that invasive alien predators (IAP) may not be recognized as enemies by native prey, or that effective antipredator responses may be absent (Cox and Lima 2006, Banks and Dickman 2007), resulting in greater hunting efficiency of predators (Kiesecker and Blaustein 1997, Gomez-Mestre and Díaz-Paniagua 2011), and potentially devastating effects for prey populations (Cruz et al. 2006, Arribas et al. 2014). It is often assumed that prey naiveté largely explains the success of IAP and their harmful ecological impacts, but this idea has only recently become the focus of empirical research (Cox and Lima 2006, Paolucci et al. 2013). 
Previous attempts to test the prey naiveté hypothesis have provided contradictory results (for a review see: Sih et al. 2010), but there are several potential problems that need to be considered. First, previous studies generally relied on testing native prey species' response to only one IAP species compared to specimens of only one native predator species. This one-to-one comparison is problematic because prey can respond differently even to various native predators (e.g., Relyea 2001a, Freeman et al. 2009). Second, many studies compared responses of prey to native and invasive predators that were phylogenetically unrelated and ecologically divergent, even though the strength and type of optimal responses may vary depending on the predators' ecological characteristics, such as their foraging mode, prey-capture mechanism, dangerousness, or microhabitat preferences (sensu Hettyey et al. 2011, Miehls et al. 2014). Third, only a few studies considered the time since the invasion occurred, even though effects of IAP are expected to vary with time since invasion due to phenotypic plasticity and genetic adaptations both in the IAP and the native prey species (Strauss et al. 2006, Hawkes 2007, Mitchell et al. 2010). Finally, many previous studies measured antipredator responses to IAP in only one population, although these responses may vary spatially due to their dependence on the local intensity of selection and on the genetic variation available for selection to act on (Strauss et al. 2006). For these reasons, more comprehensive tests of the prey naiveté hypothesis are needed to allow for better forecasting effects of biological invasions.

To test the prey naiveté hypothesis, we conducted a common garden experiment using an aquatic prey species - larvae of the agile frog (Rana dalmatina) - collected as eggs from several different populations, and we compared their antipredator responses to several native and invasive predatory fish species. In the aquatic environment, chemical cues are considered the most important sensory modality of predator recognition (Kats and Dill 1998), and therefore, we examined the behavioral responses of tadpoles presented with chemical cues from different potential predatory fishes. We assessed the importance of the history of coexistence between fish predators and their anuran prey, while controlling for ecological similarities and phylogenetic relationships among predators. We did this by exposing tadpoles to the smell of fishes that have been present in the region for varying time periods and by studying behavioral responses of tadpoles originating from fish-exposed and fish-free habitats. Because the recent feeding history of predators may strongly influence their conspicuousness towards prey (Laurila et al. 1997, Schoeppner and Relyea 2005, Hettyey et al. 2015), we also tested whether the diet of fishes affected the ability of tadpole prey to recognize native, as well as invasive fishes as predators.

We tested the prediction that the tadpoles' antipredatory response should vary along two gradients of naiveté: (1) the longer the fish species has been present in the amphibians' habitat, the stronger response its cues should elicit (from allotopic through recent invasive, then established invasive to native), and (2) tadpoles from fish-exposed (floodplain) habitats should respond more strongly than tadpoles from fish-free (hill) habitats. We also predicted that behavioral responses of tadpoles to chemical cues on predators should vary along the gradient of invasiveness similarly in different clades of predatory fishes. Further, if the fright response to fishes is not specific to predators but generalized, we expected native herbivorous fishes to also elicit stronger responses than invasive herbivorous fishes. Finally, we predicted that the ability to recognize IAP as dangerous and respond behaviorally should be facilitated if the predator recently consumed conspecific tadpoles.

\section{Methods}

\section{Experimental design}

To assess whether tadpoles of Rana dalmatina recognize invasive predators upon first encounter, we reared tadpoles in the absence of predators and exposed them to chemical cues originating from various types of fish predators. We used predator-naive tadpoles to exclude potentially confounding effects of learning (sensu Chivers and Smith 1998). We used members of two orders of predatory fishes, Perciformes and Siluriformes. From both orders, we used specimens of a native, an established invasive, a recent invasive, and an allopatric species from a Central European point of view (for details, see Table 1). We used the native species to confirm that tadpoles respond to this predator (positive controls), and we predicted that responses to predators would diminish through the established and recent invasive to the allopatric ones. Additionally, we tested whether there are generalized responses to fishes independently of their dangerousness by also exposing tadpoles to chemical cues originating from a native and an invasive species of herbivorous Cypriniformes.

To examine the importance of the history of coexistence more closely, we collected tadpoles from two types of habitats. We sampled egg-clutches laid in three semi-permanent water bodies on the floodplain of the Danube river and in three temporary ponds in the hills of the Vienna Woods, Austria (Fig. 1; Appendix S1). Larval habitats on the floodplain were located in the alluvial forest alongside the river, less than $1.5 \mathrm{~km}$ away from the main river arm and known to come into contact a few times every year during times of high water. The recent evolutionary history of these amphibian populations is thus shared with fishes, including invasive species soon after their arrival. Hill habitats were located at higher elevation and at least $1.5 \mathrm{~km}$ away from larger streams or permanent water bodies that could connect the local frog populations to others exposed to fish. Hence, amphibians in these localities live isolated from fishes. Due to the differences in the presence of fishes in their original habitat, we expected to observe weaker responses to fishes in 
TABle 1. A list of the fish species used in the experiment.

\begin{tabular}{|c|c|c|c|c|c|c|}
\hline Order & Species & Type & Origin & $N$ & Mass & Treatment \\
\hline- & - & Aged tapwater control & - & 6 & - & 1 \\
\hline Cypriniformes & Scardinius erythrophthalmus & Native & Commerce & 3 & $26.7 \pm 14.1$ & 2 \\
\hline Cypriniformes & Ctenopharyngodon idella & Invasive ( 45 years*) & Fishery in A & 3 & $34.0 \pm 8.5$ & 3 \\
\hline Perciformes & Perca fluviatilis & Native & Commerce & 6 & $42.5 \pm 11.7$ & 4,12 \\
\hline Perciformes & Lepomis gibbosus & Invasive $(\sim 120$ years $\dagger$ ) & Commerce & 6 & $31.2 \pm 17.7$ & 5,13 \\
\hline Perciformes & Neogobius melanostomus & Invasive ( 10 years $\$)$ & Danube in A & 6 & $12.5 \pm 6.6$ & 6,14 \\
\hline Perciformes & Lepidiolamprologus elongatus & Allopatric & KLIVV & 6 & $18.0 \pm 8.6$ & 7,15 \\
\hline Siluriformes & Silurus glanis & Native & Commerce & 6 & $27.5 \pm 4.4$ & 8,16 \\
\hline Siluriformes & Ameiurus nebulosus & Invasive ( 120 years§) & Commerce & 4 & $41.8 \pm 6.0$ & 9,17 \\
\hline Siluriformes & Ameiurus melas & Invasive $(\sim 15$ years $\uparrow)$ & Fishery in $\mathrm{H}$ & 6 & $18.2 \pm 2.5$ & 10,18 \\
\hline Siluriformes & Clarias batrachus & Allopatric & Commerce & 5 & $6.6 \pm 3.4$ & 11,19 \\
\hline
\end{tabular}

Notes: Cypriniform fishes were used as herbivorous controls, perciform and siluriform fishes as predators. We chose fishes to represent native, established invasive, recent invasive or allopatric species and obtained them either commercially from aquarist shops, or caught them from the Danube in Lower Austria or from fisheries in Hungary (H) or Austria (A). Differences in the number of fish per species are due to mortality before the start of experimental trials and, in the case of the herbivorous cyprinids, to only one type of food provided. Treatment number in the case of the predatory fishes depended on the food (bloodworms or tadpoles). Mean mass $(\mathrm{g}) \pm \mathrm{SD}$ are presented.

* Hauer (2007).

$\uparrow$ Muus and Dahlström (1981).

\pm Wiesner et al. (2000).

$\S$ Arnold (1990).

- Schmutz et al. (1995).

general and especially to invasive fish species in tadpoles originating from hill populations than in tadpoles from the floodplain populations (for analogous results on responses by prey that are syntopic or allotopic with predators see Kiesecker and Blaustein 1997, Hartman and Lawler 2014, Nunes et al. 2014a).

To further investigate the factors that facilitate predator recognition, we manipulated the recent feeding history of predators by feeding half of the predatory fish with bloodworms (larval Chironomus sp.), and the other half with $R$. dalmatina tadpoles. Tadpoles are known to respond behaviorally to chemical cues originating from injured conspecifics, but their responses are generally weak to similar cues released by phylogenetically unrelated prey (Laurila et al. 1997, Schoeppner and Relyea 2005, Hettyey et al. 2015). We predicted that tadpoles would respond to chemical cues originating from all predators fed with conspecifics (for a review, see Chivers and Smith 1998). In the case of bloodworm-fed predators, we expected tadpoles to respond to native predators if they were able to perceive continually released predator-borne cues (Schoeppner and Relyea 2005, Hettyey et al. 2015), and perhaps to established invasive predators, but not to recent invasive or allopatric predators (Marquis et al. 2004, Nunes et al. 2013).

We used tadpoles originating from six populations and presented them with 19 types of chemical stimuli, comprising the 19 treatments: aged tap water (control, treatment 1), stimulus water from two types of spinach-fed herbivores (treatments 2-3), from eight types of bloodworm-fed predators (treatments 4-11), and from eight types of tadpole-fed predators (treatments 12-19;
Table 1). We tested for a decrease in tadpole locomotor activity, which usually enhances prey survival by lowering prey detectability and predator encounter rates, and is a frequently observed behavioral response to predators in prey in general and in R. dalmatina tadpoles specifically (Lima and Dill 1990, Teplitsky et al. 2003, Hettyey et al. 2011).

\section{Collection and maintenance of animals}

We collected 50 eggs from each of ten freshly laid eggclutches of $R$. dalmatina from each of three floodplain and three hill populations, all located in Lower Austria (Fig. 1; Appendix S1). Populations were relatively large (>80 egg clutches laid in the same water body) and were separated from each other by $>10 \mathrm{~km}$. Eggs were laid a few days later in the hill populations than in the floodplain populations, but this did not translate into systematically earlier developmental stages at the time when we performed trials (in both groups, developmental stage: range $=28-30$, median $=29$; Mann - Whitney $U=215.5$, $N=42, P=0.94)$. We transported eggs from the field to the Konrad Lorenz Institute of Ethology (KLIVV) in Vienna.

To provide semi-natural conditions during embryonic and larval development, we constructed outdoor mesocosms 2 weeks before egg collection. We filled 60 rectangular 45-L boxes placed outdoors at the KLIVV with $25 \mathrm{~L}$ of tap water and covered them with mosquito netting. Two days later, we added $10 \mathrm{~g}$ of dried beech leaves (Fagus sylvatica) to each mesocosm to enhance spatial heterogeneity and provide nutrients for tadpoles, 


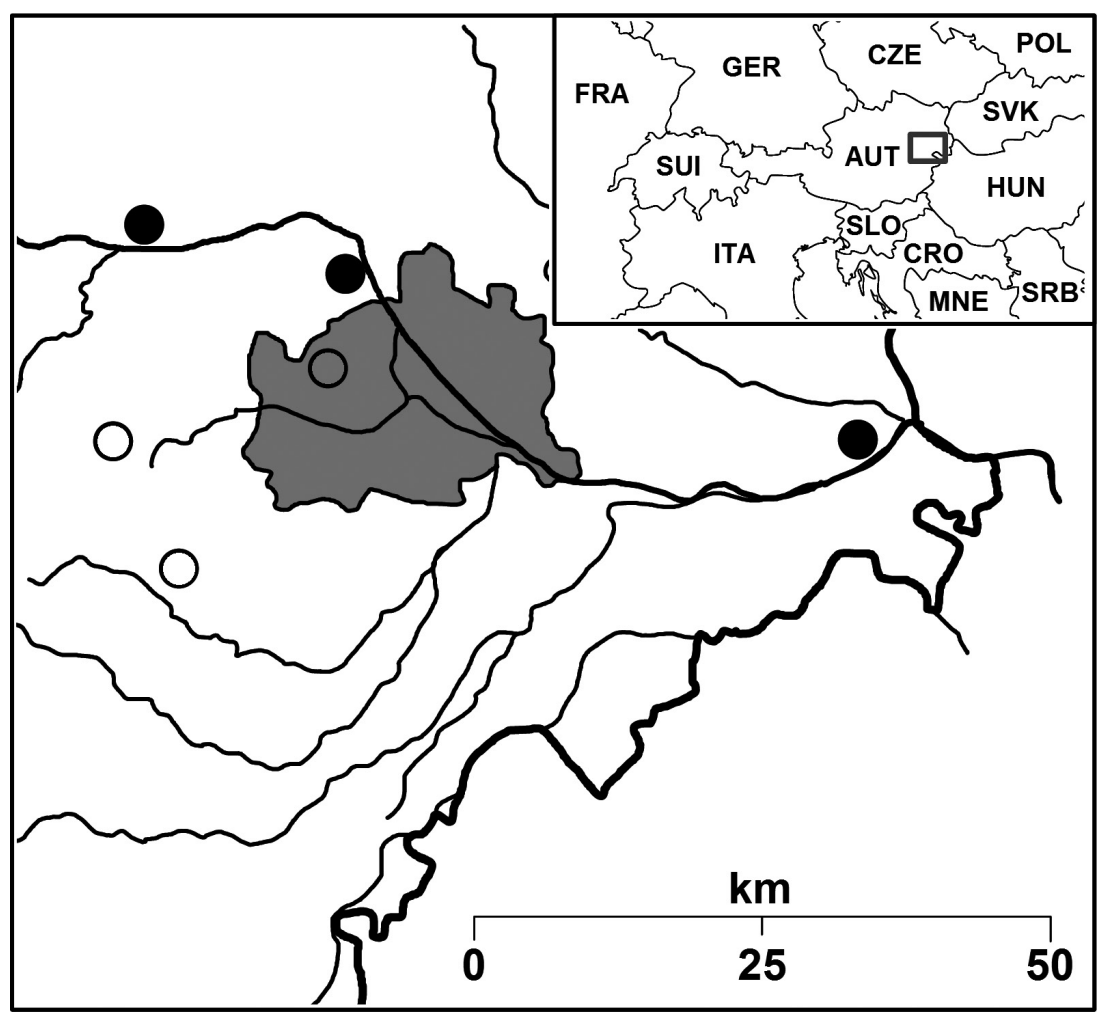

FIG. 1. Geographic location of the sampled populations around Vienna (shaded area), Austria. Floodplain populations are represented by filled circles, hill populations by empty circles.

and $1 \mathrm{~L}$ of pond water containing phyto- and zooplankton to enhance algal growth and maintain high water quality. One day before egg collection, we hung an egg-holding dish $(16 \times 13 \times 13 \mathrm{~cm})$ made of a plastic frame and mosquito-net walls into each mesocosm. After collecting eggs, we placed partial clutches into egg-holding dishes and reared embryos until hatching. Each box received eggs of only one family, and boxes were arranged into 10 spatial blocks, where each block received eggs from one family per sampled population. Three days after hatching, when tadpoles reached the free-swimming state (developmental stage 25; Gosner 1960), we released 30 haphazardly chosen healthy-looking tadpoles from egg-holding dishes into each mesocosm. We removed egg-holding dishes and transferred surplus tadpoles into large plastic containers, where we maintained them until using them as predator food.

We obtained fish from various sources (see Table 1) and maintained them in 10 aerated 100-L tanks, each tank holding six individuals of one species. By ordering specimens of similar sizes and later selecting individuals from the stock populations that were as similar in size across species as possible, we aimed to minimize amongspecies differences in body size. However, some variation was unavoidable due to logistical constraints (see Table 1). Nonetheless, predatory fish were large enough to pose an immense threat for tadpoles, as they consumed several tadpoles within a few minutes during feeding immediately before commencement or after termination of trials. We fed predatory fish with bloodworms and cypriniforms with spinach daily ad libitum and changed water every other day. Two days before the start of experimental trials, we separated fish and placed them individually into aquaria of $4,12,20$, or $45 \mathrm{~L}$, depending on the size of the fish. We filled aquaria with $\sim 0.5 \mathrm{~L}$ aged tap water/g fish body weight and fed fish with $\sim 13 \mathrm{mg}$ food $/ \mathrm{g}$ fish body weight (2-14 tadpoles or 7-47 bloodworms or 108-756 mg spinach). We adjusted aquarium size, water volume, and the quantity of food to the size of predators to obtain roughly similar cue concentrations in all treatments. We used the fish holding water in the aquaria as stimulus water in experimental trials.

\section{Experimental procedures}

We started the experimental trials 4 weeks after hatching, when the tadpoles were between developmental stages 28-30 (Gosner 1960). On the day preceding trials, we fed fish at 17:00 as described previosuly. On the day of trials, we removed leftover food from fish tanks between 8:30 and 9:00. Subsequent procedures were very similar to those employed successfully in previous studies (e.g., Ferrari et al. 2008, Mathis et al. 2008). We set up 19 dishpans $(16 \times 12 \times 7.5 \mathrm{~cm})$, corresponding to the 19 
treatments, under a USB-camera and filled them with 0.3-L aged tap water. We captured 19 haphazardly selected tadpoles from one mesocosm at a time and entered them individually into the dishpans. Tadpoles were haphazardly allocated to treatments. Each population was represented by 10 tadpoles originating from 10 different clutches, resulting in 10 replicate tadpoles per population in each treatment. We let tadpoles acclimate for $45 \mathrm{~min}$. Ten minutes before the start of behavioral recordings, we took $3 \mathrm{~mL}$ of stimulus water using $10 \mathrm{~mL}$ syringes, each one assigned to one treatment. Resulting concentrations of chemical cues in the experimental dishpans corresponded to $0.26 \mathrm{mg} / \mathrm{L}$ consumed tadpole tissue and $20 \mathrm{mg} / \mathrm{L}$ fish, exceeding concentrations that have previously been shown to elicit antipredator responses (e.g., Mathis et al. 2008, McCoy et al. 2012). We took stimulus water from one randomly selected fishholding tank within each treatment, and did this immediately before addition to focal tadpoles' dishpans to prevent cue degradation (Van Buskirk et al. 2014). Once the 45-min acclimation period was over, we videorecorded the movements of tadpoles for $5 \mathrm{~min}$, thereafter adding the stimulus water and recording movements for another $5 \mathrm{~min}$. We recorded tadpoles' behavior by photographing them every $2 \mathrm{~s}$, and from these images, we counted the number of positional changes between frames to estimate tadpole activity. The assistant scoring tadpole movement was blind with respect to treatments. After video-recording them, we over-anesthetized tadpoles and fixed three haphazardly chosen individuals from each group of 19 in $30 \%$ ethanol for later determination of developmental stage using a binocular microscope. Tadpoles were very similar in their developmental stage within families, because tadpoles were only exposed to different treatments during the $10 \mathrm{~min}$ of videorecording and before that they were raised together under identical conditions at relatively low density. We tested tadpoles collected from two randomly selected mesocosms simultaneously in two parallel experimental setups (two sets of 19 dishpans arranged on two separate tables overseen by two webcams) to increase throughput and thereby avoid large differences in the developmental state of tadpoles. We performed this procedure with tadpoles taken from all rearing mesocosms over the course of three consecutive days. After termination, we euthanized fish and remaining tadpoles with MS-222.

\section{Statistical analyzes}

We tested 1,083 tadpoles from 57 families, which was fewer than planned, as embryos failed to develop in one clutch from each hill population. For the stimulus water, we aimed to use three individual fish in each feeding $\times$ species combination, but three individuals died before the start of trials (two A. nebulosus and one C. batrachus), leaving 51 individual fish (see Table 1). By chance, two more fish (one $P$. fluviatilis, one A. melas) were not selected by the randomization on any day. Four fish did not eat tadpoles (two L. elongatus, one S. glanis, one $P$. fluviatilis) and one did not eat bloodworms (L.elongatus) at the feeding precedingtrials. Consequently, we excluded experimental trials from the analyzes in which stimulus water originated from these five individual fish, thus we analyzed the data of 988 tadpoles.

From the recordings, we excluded the first minute after start, and $1 \mathrm{~min}$ before and $1 \mathrm{~min}$ after the addition of stimulus water to avoid the inclusion of tadpole movements potentially due to disturbance, i.e., while observers were present in the experimental room. Consequently, we counted movements over 3 min prior and 4 min after the addition of chemical cues. We used the mean activity over the 3-min prestimulus period ("prestimulus activity") as a measure of baseline activity, and the mean activity over the 4-min poststimulus period ("poststimulus activity") as a measure of response to the stimulus. To validate that tadpoles responded to the stimuli in general by decreasing their activity, we compared pre- and poststimulus activity by a linear mixed-effects (LME) model with the nested random-effects structure of tadpole ID in family in population. To test whether baseline activity was similar in all treatment groups, we analyzed prestimulus activity as a dependent variable in a LME model which included treatment type as a fixed factor, and tadpole family nested in population of origin as random factors. We used a similar LME model to compare the prestimulus activity of hill and floodplain tadpoles.

To answer our main research questions, we analyzed poststimulus activity as a dependent variable using LME models, in which we included tadpole family nested in population of origin as random factors. The initial model contained treatment type (treatments 1-19) and tadpole habitat (floodplain or hill) as fixed factors, prestimulus activity as a covariate, and all two-way and three-way interactions of these three predictors. Additionally, the model contained the following fixed effects as potentially confounding variables: date as a fixed factor, and time of day and fish mass as covariates. We reduced the initial model stepwise by excluding the term with the largest $P$ value in each step until only significant $(P<0.05)$ variables and interactions remained in the final model. We checked our models by diagnostic plots and found no outliers or deviation from normality and homoscedasticity of the residuals.

For the treatments that elicited an antipredatory response according to the LME results, we calculated linear contrasts to compare the treatment effects separately in floodplain and hill tadpoles. Specifically, we estimated the slopes of relationship between pre- and poststimulus activity for each habitat $\times$ treatment group combination from a LME model that included the three-way interaction of treatment type, habitat type, and prestimulus activity, and also contained the confounding effects that were significant in our final model. From these slopes, we estimated the control-treatment difference for each treatment group, separately in floodplain and hill tadpoles. All analyses were run in R 3.1.0 
(R Core Team 2014), using the package 'nlme'; for linear contrasts we used the 'lsmeans' package. $F$-tests were calculated with 'anova' (type-III sum of squares); qualitatively identical results were obtained from $F$-tests based on Kenward-Roger approximation, using the 'pbkrtest' package (Appendix S2).

\section{RESULTS}

Tadpoles' mean activity decreased from $11.37 \pm 0.62$ movements per minute prestimulus to $7.02 \pm 0.62$ movements per minute poststimulus (mean $\pm \mathrm{SE}$; LME: $t_{987}=23.9, P<0.001$ ), and there was no significant difference in prestimulus activity among treatment groups (LME, $\left.F_{18,913}=1.23, P=0.228\right)$. Although hill tadpoles tended to show higher prestimulus activity $(12.73 \pm 0.33)$ than floodplain tadpoles $(10.16 \pm 0.31)$, this difference was nonsignificant (LME, $\left.F_{4,931}=4.73, P=0.095\right)$.

Variation in poststimulus activity was explained by date, time of day, and interactions of prestimulus activity with treatment type and tadpole habitat type (Table 2; Appendix S3). The tadpoles responded to the stimulus by reducing their activity, i.e., the slopes of poststimulus activity with prestimulus activity were $<1$ in all but one of the treatment groups (Fig. 2; Appendix S4 and Appendix S5). For tadpoles with zero prestimulus activity, poststimulus activity was also low and did not differ significantly between the control group and the other treatment groups, as shown by the nonsignificant differences in the intercept values (lines 7-24 in Appendix S3; Fig. 2). However, as the prestimulus activity increased, the difference between certain treatment groups increased, which is shown by the differences of the slopes (given by the interaction parameters in lines 26-43 of Appendix S3; Fig. 2). For most treatment groups, neither the intercept nor the slope differed from the control, meaning that poststimulus activity did not differ from control at any

TABLE 2. Analysis-of-variance table calculated from Waldtests for the final LME model (in bold) of poststimulus activity, including tadpole family $(n=57)$ nested in tadpole population $(n=6)$ as random factors $(n=988$ tadpoles). Statistics for nonsignificant terms (in italics) were calculated by re-including them into the final model.

\begin{tabular}{lrrr}
\hline \hline & \multicolumn{1}{c}{$F$} & \multicolumn{1}{c}{$\mathrm{df}$} & \multicolumn{1}{c}{$P$} \\
\hline Date & $\mathbf{5 . 1 5}$ & $\mathbf{2 , 4 8}$ & $\mathbf{0 . 0 0 9}$ \\
Time of day & $\mathbf{5 . 6 2}$ & $\mathbf{1 , 4 8}$ & $\mathbf{0 . 0 2 2}$ \\
Prestimulus activity & $\mathbf{3 5 . 0 9}$ & $\mathbf{1 , 8 9 3}$ & $<\mathbf{0 . 0 0 1}$ \\
Treatment & $\mathbf{0 . 3 4}$ & $\mathbf{1 8 , 8 9 3}$ & $\mathbf{0 . 9 9 6}$ \\
Habitat & $\mathbf{3 . 0 3}$ & $\mathbf{1 , 4}$ & $\mathbf{0 . 1 5 7}$ \\
Prestimulus & $\mathbf{2 . 3 7}$ & $\mathbf{1 8 , 8 9 3}$ & $\mathbf{0 . 0 0 1}$ \\
activity $\times$ Treatment & & & \\
Prestimulus activity $\times$ Habitat & $\mathbf{8 . 1 8}$ & $\mathbf{1 , 8 9 3}$ & $\mathbf{0 . 0 0 4}$ \\
Treatment $\times$ Habitat & 0.95 & 18,875 & 0.511 \\
Prestimulus & 1.45 & 18,857 & 0.099 \\
activity $\times$ Treatment $\times$ Habitat & & & \\
Fish mass & 0.30 & 1,892 & 0.583 \\
\hline
\end{tabular}

value of prestimulus activity. However, two treatment groups had significantly different slopes compared to the control group (lines 36-37 in Appendix S3), i.e., as prestimulus activity increased, the difference in poststimulus activity increased, as shown by the increasingly divergent regression lines in Fig. 2 (comparing panel "a" to panels "d1-d2") and Fig. 3. Specifically, tadpoles that received cues from the tadpole-fed native perciform fish had significantly reduced poststimulus activity compared to the control group when they made more than $\sim 8$ prestimulus movements per min (Fig. 3), while tadpoles exposed to cues from the tadpole-fed established-invasive perciform fish had significantly reduced poststimulus activity compared to the control group when they made more than $\sim 15$ prestimulus movements per min (Fig. 3). Thus, $\sim 65 \%$ and $40 \%$ of tadpoles clearly responded to these respective two treatments; the remaining tadpoles were either unresponsive or their response was not detectable due to their low prestimulus activity. Other treatments (i.e., cues from herbivorous Cypriniformes, predators that had been fed with bloodworms, all Siluriformes, and recent invasive and allopatric Perciformes that had been fed with tadpoles) did not elicit significantly stronger responses than the addition of tap water (Fig. 2; Appendix S3 and Appendix S4).

Hill and floodplain tadpoles did not differ significantly in poststimulus activity if their prestimulus activity was zero (line 6 in Appendix S3), but the slopes with prestimulus activity were significantly less steep for floodplain tadpoles than for hill tadpoles (line 25 in Appendix S3; Fig. 2), meaning that poststimulus activity became increasingly higher in hill tadpoles than in floodplain tadpoles as prestimulus activity increased. This habitat difference was relatively consistent across treatments, i.e., the three-way interaction between treatment, habitat, and prestimulus activity was nonsignificant (Table 2). In the two treatments that elicited an antipredatory response, linear contrasts showed that floodplain tadpoles responded significantly stronger to the predator cues than to tap water in the treatments with tadpole-fed native Perciformes (difference between slopes: $0.36 \pm 0.18, P=0.048)$ and established invasive Perciformes $(0.34 \pm 0.17, P=0.045)$, whereas the response of tadpoles from hill populations to the same two treatments was marginally nonsignificant $(0.32 \pm 0.18$, $P=0.076)$ and nonsignificant $(0.16 \pm 0.16, P=0.305)$, respectively. Poststimulus activity increased over the day but decreased with date (Appendix S3), whereas it was unrelated to fish mass (Table 2).

\section{DisCusSION}

Predator-naive larvae of Rana dalmatina responded to chemical cues of native or established invasive perciform fish predators, though only if the fish had recently been fed conspecific larvae, whereas the tadpoles ignored chemical stimuli from recent invasive and allopatric perciforms, even when cues of injured tadpoles were present 
Control

a) No fish

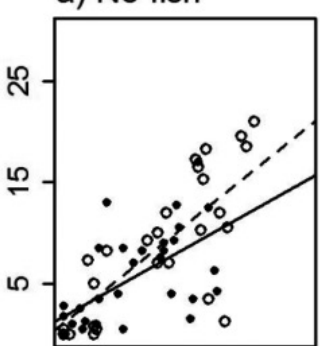

a) No fish

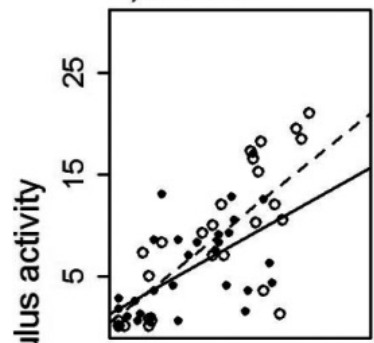

a) No fish

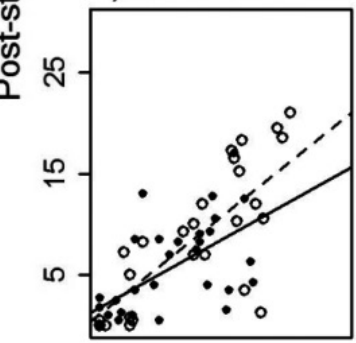

a) No fish

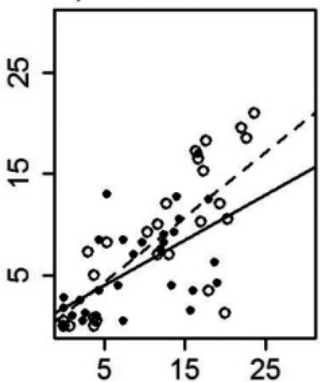

Native
Recent

invasive
Allotopic

b) Perciformes, bloodworm-fed

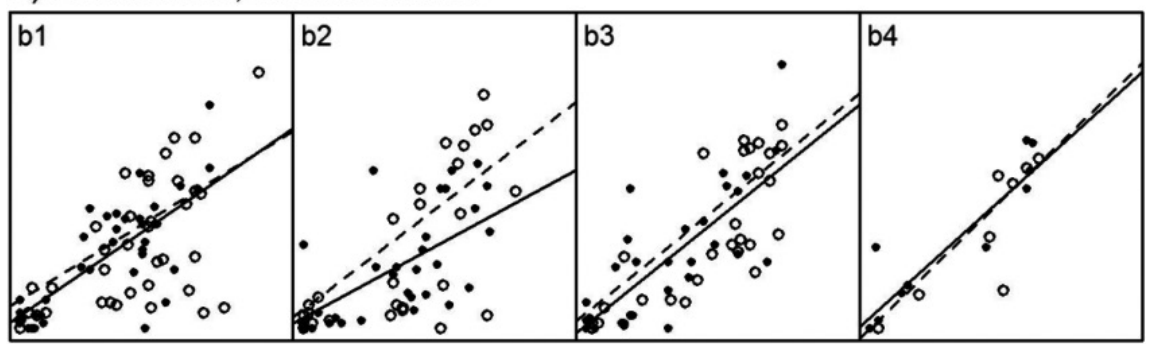

c) Siluriformes, bloodworm-fed

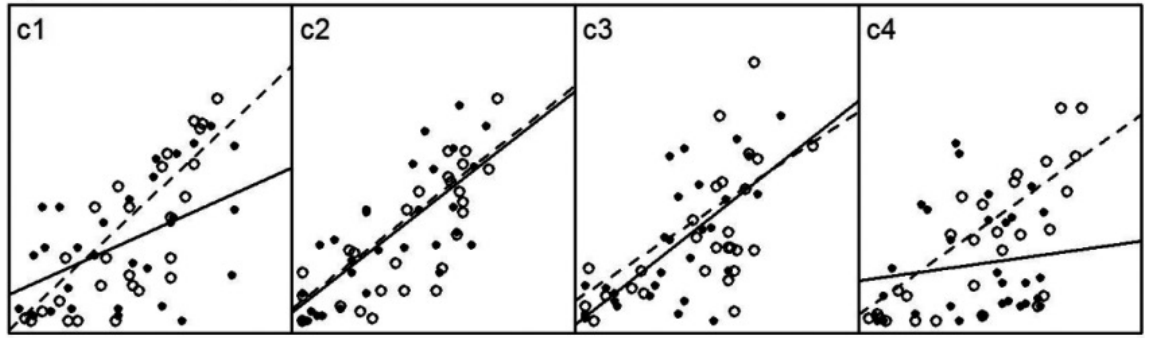

d) Perciformes, tadpole-fed

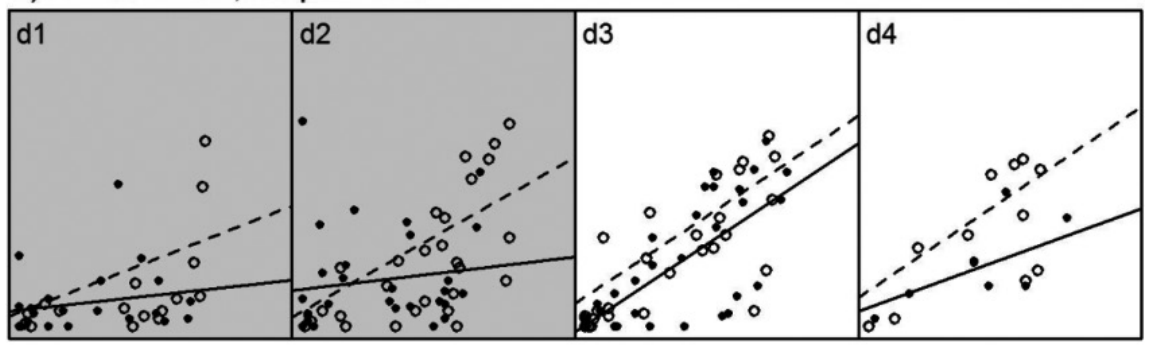

e) Siluriformes, tadpole-fed

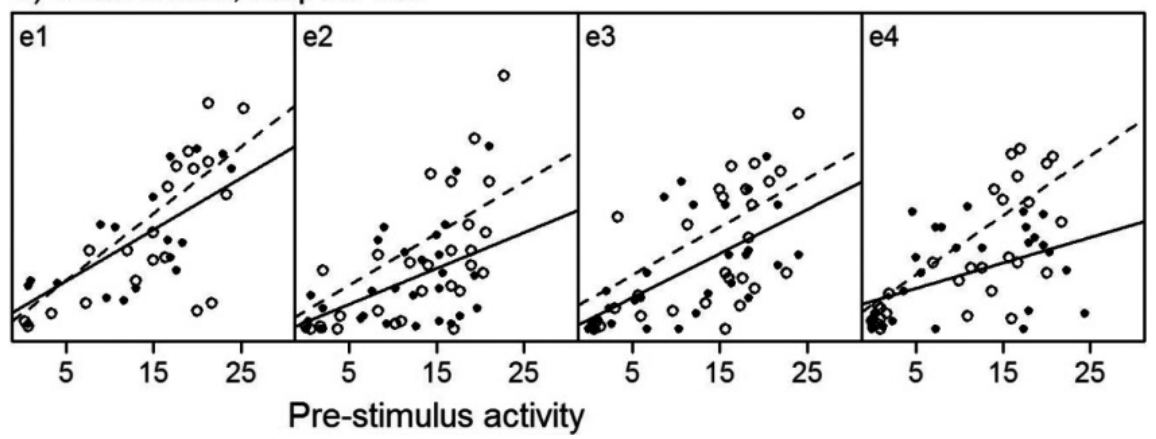

FIG. 2. Poststimulus activity in relation to prestimulus activity (number of movements per min) of tadpoles originating from floodplain (filled symbols, solid lines) and hill (empty symbols, dashed lines) populations in the control and the 16 treatments including exposure to chemical cues from predatory fishes (for nonsignificant responses to chemical cues from herbivorous fishes see Appendix S4). The control group ("no fish") is repeated in each row to facilitate control-treatment comparisons. Slopes are fitted from an LME model allowing for a three-way interaction between prestimulus activity, treatment type, and habitat type. Grey background indicates treatments in which the slope of the relationship differed significantly between the treatment group and the control group.

(see Fig. 2, panels d1-d4). Surprisingly, tadpoles did not respond to any of the siluriform predators (Fig. 2, panels e1-e4). Further, tadpoles did not decrease activity in response to cues from predators feeding on bloodworms or to herbivorous fishes fed with spinach (Fig. 2, panels b1-c4; Appendix S4). Finally, tadpoles originating from hill populations showed slightly higher prestimulus activity and significantly weaker responses to all stimuli 


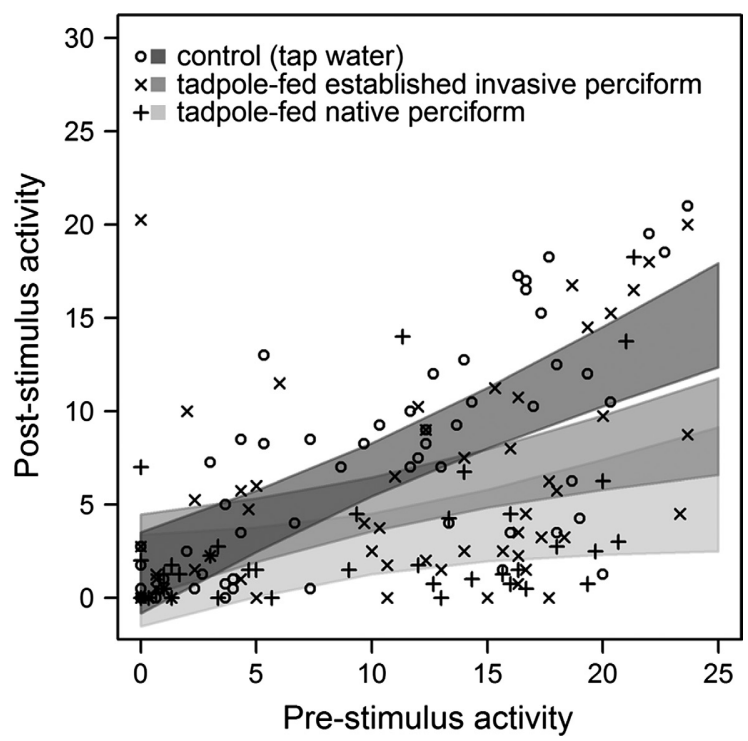

FIG. 3. Poststimulus activity in relation to prestimulus activity (number of movements per min) of tadpoles exposed to tap water (control) or the olfactory cues of native or established invasive Perciformes that had been fed with tadpoles. The shaded polygons show the $95 \%$ confidence band of the regression line in each treatment group, predicted from the final model in Appendix S3 (hill and floodplain tadpoles were combined). Where two bands do not overlap, the average response of tadpoles differs significantly between the respective two groups.

than floodplain tadpoles. Thus, our findings on perciform predators support the prey naiveté hypothesis, and show that antipredator responses of tadpoles were not elicited upon a first encounter with IAPs, not even in the presence of direct prey-borne chemical cues, unless the prey species and the IAPs share a sufficiently long co-evolutionary history.

The question arises, why didn't tadpoles respond to all predators fed with conspecifics, even though prey-borne chemical cues were clearly present. Relying on general cues of predation risk may have costs, such as reacting unnecessarily, and a response that is effective against one predator may enhance susceptibility to another (Soluk and Collins 1988, Sih et al. 1998). Consequently, there may be selection for using predator-specific cues (Sih et al. 2010). Indeed, tadpoles show weak responses to general preconsumption prey-borne cues alone (e.g., Petranka and Hayes 1998, Schoeppner and Relyea 2005, Hettyey et al. 2015), and several species seem to require a combination of general prey-borne cues and specific predator-borne cues to respond strongly to the threat of predation (Schoeppner and Relyea 2005, Hettyey et al. 2015). Thus, upon a first encounter, without the benefit of experience, tadpoles may not respond behaviorally to alien predators that are not recognized innately, not even if prey-borne cues are present. Additionally, while recognition and responses to some IAP may be effective if phylogenetically related native taxa are present in the environment (sensu Ricciardi and Atkinson 2004, Cox and Lima 2006, Sih et al. 2010), phylogenetically related native and invasive predators are not necessarily similar in terms of chemical cues or foraging mode (Chalcraft and Resetarits 2003). Taken together, these factors may explain the observed responses to tadpole-fed native and established invasive perciform predators, and the ignorance of cues from recent invasive and allopatric perciforms.

To our surprise, tadpoles did not respond to any of the siluriform predators, not even native or established invasive fishes. We do not know how to explain this unexpected finding, though we suggest it may be due to differences in the feeding behavior of the predators. There is a striking difference between the oral apparatus and the food intake mechanism of perciform and siluriform fishes in general. Both groups use suction for capturing prey, but whereas siluriform fishes engulf their prey whole, the more gape-limited perciforms often bite their prey before eventually engulfing them. Consequently, concentrations of capture-released, prey-borne cues may be higher in the presence of feeding perciform predators than in that of siluriform fishes, hence the stronger response to the former (sensu Ferrari et al. 2007). Also, siluriform fishes may have evolved stealth adaptations for inactivating prey-borne cues during digestion (Feminella and Hawkins 1994, Chivers and Smith 1998, Miller et al. 2016), hence the inability of tadpoles to sense that conspecifics had been consumed and digested by siluriform predators. These are merely speculations and the lack of behavioral responses to siluriform predators requires further investigation.

Tadpoles did not reduce their activity in response to chemical cues from the herbivorous fishes or to any of the bloodworm-fed predators (controls). These findings further support the conclusion that $R$. dalmatina tadpoles lack a generalized fright response to fishes, unlike some other prey taxa (e.g., Langerhans and DeWitt 2002, Gherardi et al. 2011). When predators search for and feed on alternative prey, unresponsive prey may spare costs arising from lowered activity without elevating the risk of being preyed upon (Lima and Dill 1990, Wilson and Lefcort 1993, Persons et al. 2001). Indeed, several studies on tadpoles have found weak or no responses to predators that had been feeding on phylogenetically distantly related prey (Laurila et al. 1997, Schoeppner and Relyea 2005, Hettyey et al. 2015). Hence, a response to chemical cues from recent invasive predators may only be elicited in the simultaneous presence of attack-, capture-, or digestion-released prey-borne cues originating from conspecific or closely related prey (Marquis et al. 2004, Nunes et al. 2013).

The lower activity and stronger inducible responses of floodplain tadpoles may be explained by local adaptation, as anurans on the floodplain are exposed to fishes, whereas hill populations do not coexist with fishes. The low baseline activity and strong inducible responses to fishes may be selectively maintained in floodplain populations as an adaptation to lower encounter rates with 
fish predators, which are the most voracious aquatic predators of anuran larvae (Semlitsch 1993, Relyea 2001b). At the same time, the lack of predatory fishes in hill populations may lead to an evolutionary loss of fearfulness (for similar results see Magurran 1990, Kiesecker and Blaustein 1997). It is unlikely that these differences among tadpole populations were due to adaptations to microclimatic differences arising from varying altitudes, because hill ponds were located only $\sim 250 \mathrm{~m}$ higher than floodplain populations on average. Variation in tadpole age could not explain our findings either, as there were no systematic differences in the developmental state of tadpoles originating from lowland and from hill populations at the time when we performed trials.

The spread of IAP may be viewed as natural experiments, which can be used to assess the pace of contemporary microevolution (sensu Hendry and Kinnison 1999). For example, recognition of IAP and adaptive inducible responses have been reported to appear after only $15 \mathrm{yr}$ in a native mussel and invasive crab system (Freeman and Byers 2006). Nunes et al. (2013, 2014a, b) documented constitutive and inducible changes in behavior, morphology and life history in the larvae of several frog species in response to an invasive crayfish within 30 years. These and other reports (for reviews see Hendry and Kinnison 1999, Strauss et al. 2006) suggest that IAP impose evolutionary changes in their prey within a few generations. Given that the generation time of $R$. dalmatina is $\sim 4$ yr (Riis 1997, Sarasola-Puente et al. 2011), their antipredatory response to the established invasive perciform predator (present for $\sim 120$ years) has apparently evolved within 30 generations. Taking advantage of the recent linear spread of invasive fish predators along water drainage systems would allow for more precisely estimating the speed of predator recognition evolution.

In summary, our study shows that the innate ability of tadpole prey to detect and respond to IAP depends upon how long the predator and prey have been in contact with each other. Tadpoles did not respond to chemical cues of any recent invasive or allopatric predators, whereas they lowered their activity when exposed to native and established invasive perciforms, but not to any siluriforms. This result indicates that time since arrival of the IAP to the geographic region may be an important factor; significant evolutionary changes in the predator-recognition ability of prey may evolve in fewer than 30 generations but appear to take more than 3-4 generations. Also, tadpoles originating from hill ponds devoid of fish predators exhibited weaker responses towards all fishes than tadpoles originating from fish-exposed floodplain populations. This result supports the hypothesis that the presence of predators that are phylogenetically and ecologically similar to the IAP may precondition prey, lowering their mortality upon arrival of the IAP. Further, the observation that tadpoles did not respond to any of the siluriform predators while they did lower their activity in response to some perciforms emphasizes the need for a careful selection of multiple study species in similar studies. Finally, since tadpoles ignored all predators that had not fed on conspecifics, but responded to some of those that had consumed conspecifics, it appears that the diet of predators is also crucial for predator-recognition and triggering off a response. Our results have important implications for the interpretation of previous studies and for the design of future investigations. More importantly, however, even though learning may enhance the ability of prey to recognize predators (Chivers and Smith 1998), our results are consistent with suggestions that prey naiveté contribute to the success of IAP, facilitating their spread into new environments. Nonetheless, if prey populations avoid extinction shortly after the arrival of IAP, recognition of predators and effective antipredator defensedefenses may evolve within a few generations and contribute to the co-existence of once invasive predators and their native prey.

\section{ACKNOWLEDGMENTS}

We would like to thank Bernhard Eckel and Daniel Grula for help in catching native fishes, Marc Sztatecsny and Christian Baumgartner for help in finding suitable frog populations and Márk Szederkényi for analysing video-recordings. Permissions for collection and transport of animals were issued by the City of Vienna (MA22 - 295/2012, MA45 - 1080/2012, MA49 - P4/2012, MA58 - 2048/2012/10, MA60 - 6/2008) and by the Land Niederösterreich (RU5-BE-7/012-2012). The experiment was approved by the institutional ethics committee and the national authority according to $\S 8 \mathrm{ff}$ of Law for Animal Experiments, Tierversuchsgesetz-TVG (GZ 68.205/0136-II/3b/2012). This research was supported by an FP7 Marie Curie Career Integration Grant of the European Commission (PCIG13-GA-2013-631722) and the "Lendület" Programme of the Hungarian Academy of Sciences (MTA, LP2012-24/2012). The authors have no conflict of interest to declare.

\section{Literature Cited}

Arnold, A. 1990. Eingebürgerte fischarten. Zur biologie und verbreitung allochthoner wildfische in Europa. Die neue Brehm-Bücherei, A. Ziemsen Verlag, Wittenberg, Germany.

Arribas, R., C. Díaz-Paniagua, and I. Gomez-Mestre. 2014. Ecological consequences of amphibian larvae and their native and alien predators on the community structure of temporary ponds. Freshwater Biology 59:1996-2008.

Banks, P. B., and C. R. Dickman. 2007. Alien predation and the effects of multiple levels of prey naïveté. Trends in Ecology \& Evolution 22:229-230.

Blackburn, T. M., N. Pettorelli, T. Katzner, M. E. Gompper, K. Mock, T. W. J. Garner, R. Altwegg, S. Redpath, and I. J. Grodon. 2010. Dying for conservation: eradicating invasive alien species in the face of opposition. Animal Conservation 13:227-228.

Chalcraft, D. R., and W. J. Resetarits. 2003. Predator identity and ecological impacts: Functional redundancy or functional diversity? Ecology 84:2407-2418.

Chivers, D. P., and R. J. F. Smith. 1998. Chemical alarm signalling in aquatic predator-prey systems: a review and prospectus. Ecoscience 5:338-352.

Clavero, M., and E. García-Berthou. 2005. Invasive species are a leading cause of animal extinctions. Trends in Ecology \& Evolution 20:110 
Cox, J. G., and S. L. Lima. 2006. Naiveté and an aquatic-terrestrial dichotomy in the effects of introduced predators. Trends in Ecology \& Evolution 21:674-680.

Cruz, M. J., R. Rebelo, and E. G. Crespo. 2006. Effects of an introduced crayfish, Procambarus clarkii, on the distribution of south-western Iberian amphibians in their breeding habitats. Ecography 29:329-338.

Daehler, C. C. 2003. Performance comparisons of co-occurring native and alien invasive plants: implications for conservation and restoration. Annual Review of Ecology and Systematics 34:183-211.

Davis, M. A. 2009. Invasion biology. Oxford University Press, Oxford, UK.

Feminella, J. W., and C. P. Hawkins. 1994. Tailed frog tadpoles differentially alter their feeding behavior in response to nonvisual cues from four predators. Journal of the North American Benthological Society 13:310-320.

Ferrari, M. C. O., M. R. Brown, M. S. Pollock, and D. P. Chivers. 2007. The paradox of risk assessment: comparing responses of fathead minnows to capture-released and dietreleased alarm cues from two different predators. Chemoecology 17:157-161.

Freeman, A. S., and J. E. Byers. 2006. Divergent induced responses to an invasive predator in marine mussel populations. Science 313:831-833.

Ferrari, M. C. O., F. Messier, and D. P. Chivers. 2008. Degradation of chemical alarm cues under natural conditions: risk assessment by larval woodfrogs. Chemoecology 17:263-266.

Freeman, A. S., J. Meszaros, and J. E. Byers. 2009. Poor phenotypic integration of blue mussel inducible defenses in environments with multiple predators. Oikos 118:758-766.

Gherardi, F., K. M. Mavuti, N. Pacini, E. Tricarico, and D. M. Harper. 2011. The smell of danger: chemical recognition of fish predators by the invasive crayfish Procambarus clarkii. Freshwater Biology 56:1567-1578.

Gomez-Mestre, I., and C. Díaz-Paniagua. 2011. Invasive predatory crayfish do not trigger inducible defensedefenses in tadpoles. Proceedings of the Royal Society of London B: Biological Sciences 278:3364-3370.

Gosner, K. L. 1960. A simplified table for staging Anuran embryos and larvae with notes on their identification Herpetologica 16:183-190.

Hartman, R., and S. Lawler. 2014. Evidence for contemporary evolution of behavioral responses to introduced fish. Animal Behavior 97:213-220.

Hauer, W. 2007. Fische, krebse, muscheln in heimischen seen und flüssen. Leopold Stocker Verlag, Graz, Austria.

Hawkes, C. V. 2007. Are invaders moving targets? The generality and persistence of advantages in size, reproduction, and enemy release in invasive plant species with time since introduction. American Naturalist 170:832-843.

Hendry, A. P., and M. T. Kinnison. 1999. The pace of modern life: measuring rates of contemporary microevolution. Evolution 53:1637-1653.

Hettyey, A., Z. Tóth, K. E. Thonhauser, J. G. Frommen, D. J. Penn, and J. Van Buskirk. 2015. The relative importance of prey-borne and predator-borne chemical cues for inducible antipredator responses in tadpoles. Oecologia 179:699-710.

Hettyey, A., K. Vincze, S. Zsarnóczai, H. Hoi, and A. Laurila. 2011. Costs and benefits of defensedefenses induced by predators differing in dangerousness. Journal of Evolutionary Biology 24:1007-1019.

Kats, L. B., and L. M. Dill. 1998. The scent of death: chemosensory assessment of predation risk by prey animals. Ecoscience $5 \cdot 361-394$.
Keane, R. M., and M. J. Crawley. 2002. Exotic plant invasions and the enemy release hypothesis. Trends in Ecology \& Evolution 17:164-170.

Kiesecker, J. M., and A. R. Blaustein. 1997. Population differences in responses of red-legged frogs (Rana aurora) to introduced bullfrogs. Ecology 78:1752-1760.

Langerhans, R. B., and T. J. DeWitt. 2002. Plasticity constrained: over-generalized induction cues cause maladaptive phenotypes. Evolutionary Ecology Research 4:857-870.

Laurila, A., J. Kujasalo, and E. Ranta. 1997. Different antipredator behavior in two anuran tadpoles: effects of predator diet. Behavioral Ecology and Sociobiology 40:329-336.

Lima, S. L., and L. M. Dill. 1990. Behavioral decisions made under the risk of predation: a review and prospectus. Canadian Journal of Zoology 68:619-640.

Magurran, A. E. 1990. The inheritance and development of minnow anti-predator behavior. Animal Behavior 39: 834-842.

Marquis, O., P. Saglio, and A. Neveu. 2004. Effects of predators and conspecific chemical cues on the swimming activity of Rana temporaria and Bufo bufo tadpoles. Archiv für Hydrobiologie 160:153-170.

Mathis, A., M. C. O. Ferrari, N. Windel, F. Messier, and D. P. Chivers. 2008. Learning by embryos and the ghost of predation future. Proceedings of the Royal Society of London B: Biological Sciences 275:2603-2607.

McCoy, M. W., J. C. Touchon, T. Landberg, K. M. Warkentin, and J. R. Vonesh. 2012. Prey responses to predator chemical cues: disentangling the importance of the number and biomass of prey consumed. PLoS ONE 7:e47495.

McGeoch, M. A., S. H. M. Butchart, D. Spear, E. Marais, E. J. Kleynhans, A. Symes, J. Chanson, and M. Hoffmann. 2010. Global indicators of biological invasion: species numbers, biodiversity impact and policy responses. Diversity and Distributions 16:95-108.

Miehls, A. L. J., S. D. Peacor, and A. G. McAdam. 2014. Gapelimited predators as agents of selection on the defensive morphology of an invasive invertebrate. Evolution 68:2633-2643.

Miller, A. K., B. Maritz, S. McKay, X. Glaudas, and G. J. Alexander. 2016. An ambusher's arsenal: chemical crypsis in the puff adder (Bitis arietans). Proceedings of the Royal Society of London B: Biological Sciences 282:20152182.

Mitchell, C. E., D. Blumenthal, V. Jarošik, E. E. Puckett, and P. Pyšek. 2010. Controls on pathogen species richness in plants' introduced and native ranges: roles of residence time, range size and host traits. Ecology Letters 13:1525-1535.

Muus, B. J., and P. Dahlström. 1981. Süßwasserfische Europas. 5. Auflage, BLV, Wien, Austria.

Nunes, A. L., G. Orizaola, A. Laurila, and R. Rebelo. $2014 a$. Rapid evolution of constitutive and inducible defenses against an invasive predator. Ecology 95:1520-1530.

Nunes, A. L., G. Orizaola, A. Laurila, and R. Rebelo. $2014 b$. Morphological and life-history responses of anurans to predation by an invasive crayfish: an integrative approach. Ecology and Evolution 4:1491-1503.

Nunes, A. L., A. Richter-Boix, A. Laurila, and R. Rebelo. 2013. Do anuran larvae respond behaviorally to chemical cues from an invasive crayfish predator? A community-wide study. Oecologia 171:115-127.

Paolucci, E. M., H. J. MacIsaac, and A. Ricciardi. 2013. Origin matters: alien consumers inflict greater damage on prey populations than do native consumers. Diversity and Distributions 19:988-995.

Persons, M. H., S. E. Walker, A. L. Rypstra, and S. D. Marshall. 2001. Wolf spider predator avoidance tactics and survival in the presence of diet-associated predator cues (Araneae: Lycosidae). Animal Behavior 61:43-51. 
Petranka, J., and L. Hayes. 1998. Chemically mediated avoidance of a predatory odonate (Anax junius) by American toad (Bufo americanus) and wood frog (Rana sylvatica) tadpoles. Behavioral Ecology and Sociobiology 42:263-271.

R Core Team. 2014. R: A language and environment for statistical computing. R Foundation for Statistical Computing, Vienna, Austria.

Relyea, R. A. 2001a. Morphological and behavioral plasticity of larval anurans in response to different predators. Ecology 82:523-540.

Relyea, R. A. 2001b. The relationship between predation risk and antipredator responses in larval anurans. Ecology 82:541-554.

Ricciardi, A., and S. K. Atkinson. 2004. Distinctiveness magnifies the impact of biological invaders in aquatic ecosystems. Ecology Letters 7:781-784.

Riis, N. 1997. Field studies on the ecology of the agile frog in Denmark. Rana Sonderheft 2:189-202.

Sarasola-Puente, V., A. Gosá, N. Oromí, M. J. Madeira, and M. Lizana. 2011. Growth, size and age at maturity of the agile frog (Rana dalmatina) in an Iberian Peninsula population. Zoology 114:150-154.

Schmutz, S., H. Mader, and G. Unfer. 1995. Funktionalität von Potamalfischaufstiegshilfen im Marchfeldkanalsystem. Österreichische Wasser-und Abfallwirtschaft 47:43-58.

Schoeppner, N. M., and R. A. Relyea. 2005. Damage, digestion, and defense: the roles of alarm cues and kairomones for inducing prey defensedefenses. Ecology Letters 8:505-512.

Semlitsch, R. D. 1993. Effects of different predators on the survival and development of tadpoles from the hybridogenetic Rana esculenta complex. Oikos 67:40-46.

Sih, A., D. I. Bolnick, B. Luttbeg, J. L. Orrock, S. D. Peacor, L. M. Pintor, E. Preisser, J. S. Rehage, and J. R. Vonesh. 2010. Predator-prey naïveté, antipredator behavior, and the ecology of predator invasions. Oikos 119:610-621.

Sih, A., G. Englund, and D. Wooster. 1998. Emergent impacts of multiple predators on prey. Trends in Ecology \& Evolution 13:350-355.

Soluk, D. A., and N. C. Collins. 1988. Synergistic interactions between fish and stoneflies-facilitation and interference among stream predators. Oikos 52:94-100.

Strauss, S. Y., J. A. Lau, and S. P. Carroll. 2006. Evolutionary responses of natives to introduced species: What do introductions tell us about natural communities? Ecology Letters 9:354-371.

Tabak, M. A., S. Poncet, K. Passfield, J. R. Goheen, and C. Martinez del Rio. 2015. Rat eradication and the resistance and resilience of passerine bird assemblages in the Falkland Islands. Journal of Animal Ecology 84:755-764.

Teplitsky, C., S. Plénet, and P. Joly. 2003. Tadpoles' responses to risk of fish introduction. Oecologia 134:270-277.

Van Buskirk, J., A. Krugel, J. Kunz, F. Miss, and A. Stamm. 2014. The rate of degradation of chemical cues indicating predation risk: an experiment and review. Ethology 120: 942-949.

van Kleunen, M., E. Weber, and M. Fischer. 2010. A metaanalysis of trait differences between invasive and non-invasive plant species. Ecology Letters 13:235-245.

Whitney, K. D., and C. A. Gabler. 2008. Rapid evolution in introduced species, 'invasive traits' and recipient communities: challenges for predicting invasive potential. Diversity and Distributions 14:569-580.

Wiesner, C., R. Spolwind, H. Waidbacher, S. Guttman, and A. Doblinger. 2000. Erstnachweis der Schwarzmundgrundel Neogobius melanostomus (Pallas, 1814) in Österreich. Österreichischer Fisch 53:330-331.

Wilson, D. J., and H. Lefcort. 1993. The effect of predator diet on the alarm response of red-legged frog, Rana aurora, tadpoles. Animal Behavior 46:1017-1019.

\section{SUPPORTING INFORMATION}

Additional supporting information may be found in the online version of this article at http://onlinelibrary.wiley.com/ doi/10.1002/ecy.1532/suppinfo 